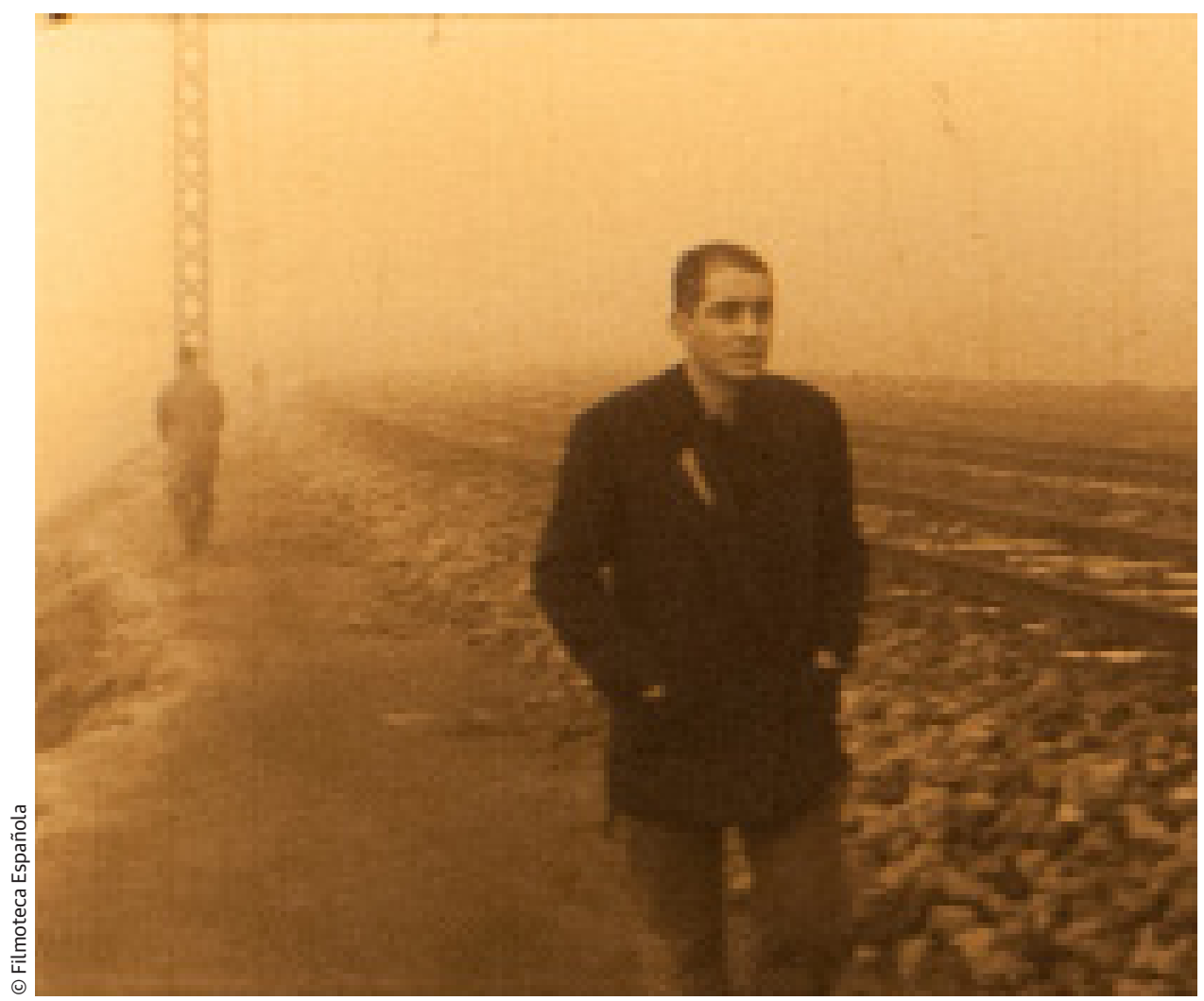

\title{
VÍCTOR ERICE EN LA ESCUELA OFICIAL DE CINEMATOGRAFÍA. ELOGIO DE LA INCOMUNICACIÓN
}

\author{
VÍCTOR ERICE AT ESCUELA OFICIAL DE \\ CINEMATOGRAFÍA. IN PRAISE OF ISOLATION
}

Luis Deltell / Ideltell@ucm.es

UNIVERSIDAD COMPLUTENSE DE MADRID 


\section{RESUMEN}

Aunque Víctor Erice es uno de los directores españoles más estudiados del cine español, sus trabajos en el Instituto de Investigaciones y Experiencias Cinematográficas, que más tarde pasará a llamarse Escuela Oficial de Cinematografía, no se han analizado en profundidad. Salvo su práctica de tercer curso, Los días perdidos, el resto de los cortometrajes y los guiones escritos se han considerado obras menores, piezas sin importancia relevante o directamente títulos extraviados. Sin embargo, estos trabajos se encuentran en buen estado en el archivo de la Escuela Oficial de Cine custodiado por la Filmoteca Española. De Víctor Erice se conservan cuatro cortometrajes y cinco guiones cinematográficos para piezas breves. En este artículo, resumen de una investigación realizada sobre dicho material inédito, se quiere mostrar cómo estas obras presentan un valor en sí mismas y deben ser analizadas como parte importante de la filmografía de este autor. En todos estos trabajos, sin dejar de ser ejercicios de escuela, se muestra la mirada de un cineasta pleno. Así, existen elementos que serán clave en el posterior universo temático y estético de Víctor Erice. Además, el creador aborda como problemática central de sus prácticas el tema de la comunicación humana, o más propiamente el de la incomunicación. En los guiones y los cortometrajes catalogados de la etapa en la EOC se observa cómo Erice, influenciado en parte por Michelangelo Antonioni, investiga estéticamente el modo de narrar y mostrar los procesos que conducen a la incomunicación y al aislamiento de sus protagonistas.

PALABRAS CLAVE

Víctor Erice, Escuela Oficial de Cinematografía, Antonioni, cine español, estudios cinematográficos

\section{ABSTRACT}

Even though Victor Erice is one of Spanish cinema's best studied directors, his film projects at the Instituto de Investigaciones y Experiencias Cinematográficas, later known as Escuela Oficial de Cinematografía, haven't been studied in depth. Except for his third-year film, "Los días perdidos", his other shorts and scripts have been considered minor works, pieces of no consequence, or are simply thought of as lost. However, these films have been well preserved at the Spanish film archive. A total of four short films and scripts are kept in the archive. This article, a summary of the research done on these unpublished pieces, aims to show how they hold value by themselves and that they must be analyzed as an important part of the author's filmography. All these projects, while being school exercises, show the gaze of a seasoned director. Some key elements of Victor Erice's themes and aesthetics are already present in them. Moreover, the artist addresses human communication, or its lack, as his main theme in his school projects. In those scripts and shorts preserved from his time at the EOC we can notice how Erice, under Michelangelo Antonioni's influence, researches through aesthetics how to narrate and show those processes that lead to the isolation and lack of communication of his main characters.

KEYWORDS Víctor Erice, Escuela Oficial de Cinematografía, Antonioni, Spanish Cinema, Film Studies. 


\section{INTRODUCCIÓN}

Víctor Erice es uno de los directores más estudiados y celebrados del cine español. Si nos atenemos a su escasa obra cinematográfica, descubrimos que es el creador hispano que ha generado más discusiones, trabajos académicos y tesis doctorales por fotograma rodado. El interés que ha despertado solo se puede comparar con el de las filmografías de Luis Buñuel y Pedro Almodóvar. Aún hoy, sus largometrajes y sus proyectos audiovisuales recientes son objetos de estudio y de análisis permanente. Sirva de ejemplo la reciente tesis doctoral de la profesora Isabel Arquero Blanco (2012), el trabajo de Santos Zunzunegui (2014) o los homenajes y ciclos internacionales como An Open Window: Víctor Erice, celebrado en julio de 2015 en Berkeley, University of California.

Sin embargo, su etapa de formación en la Escuela Oficial de Cinematografía (EOC) ha sido siempre ignorada o simplificada al análisis de Los días perdidos, práctica final en dicho centro educativo. Este abandono se debe a que los cortometrajes previos se consideraban extraviados (Latorre, 2006) o inmaduros (Cerrato, 2006), menores (Arocena, 1996) o sin "cierta entidad" (Pena, 1993). La realidad es que el archivo de la EOC custodia cinco guiones -tres de ellos inéditos- y la Filmoteca Española conserva cuatro cortometrajes no editados ni publicados en ningún formato.

Varios son los motivos de este abandono. El primero de ellos es que la Escuela Oficial de Cinematografía no ha sido tratada en profundidad y es una de las investigaciones pendientes del cine español (Aranzubia Cob y Castro de Paz, 2010). Salvo el trabajo de Lucio Blanco Mallada, que se centra principalmente en los cortometrajes finales de todos los estudiantes egresados, no existe ninguna otra investigación académica rigurosa sobre la EOC. En 1999, Francisco Llinás y un equipo de la Filmoteca Española realizaron una catalogación de las prácticas, aunque no su análisis o contextualización (Llinás, 1999) ${ }^{1}$.

Así, los años de formación de Víctor Erice - como los de Luis García Berlanga, Juan Antonio Bardem, Pilar Miró y tantos otros estudiantes del
EOC- se encuentran sumergidos en una neblina en la cual únicamente se vislumbra su práctica final. Por ello no es raro que se desconozcan los títulos, las fechas de producción o el equipo que realizó dichos filmes. Los errores y las equivocaciones sobre el contenido real de los cortometrajes son alarmantes. Sirva de ejemplo que la primera práctica de Erice se presenta hasta con siete títulos distintos. Sin embargo, estos trabajos se custodian en un buen estado de conservación y de catalogación en la Filmoteca Española y los Archivos de la EOC.

Esta investigación aborda los años de formación de Víctor Erice. Para ello analizamos sus cuatro prácticas cinematográficas y los guiones y tratamientos inéditos que se conservan en el depósito de la escuela. Nuestro propósito principal se centrar en mostrar que estos ejercicios estudiantiles son en realidad obras relevantes y de cierta importancia, ya que están bien construidas y presentan rasgos estéticos esenciales de este director. Recientes artículos, como el de Zunzunegui (2014), han planteado cómo los escritos de Erice sobre el cine revelan datos fundamentales sobre su filmografia posterior; del mismo modo, pensamos que sus proyectos filmicos iniciales desarrollan ya cuestiones temáticas y soluciones estéticas que configurarán el estilo de este creador.

Proponemos una doble metodología: primero, una contextualización histórica dentro de la EOC y, segundo, el análisis estético. En el acercamiento histórico nos atenemos al modelo planteado para el estudio de la filmografía del egresado Luis E. Torán (García Fernández, 2006), mientras que en el análisis estético proponemos un acercamiento cuantitativo y cualitativo como el realizado para la puesta en escena por David Bordwell (2005). Estos dos caminos nos permiten mostrar, por un lado, la situación de Víctor

\footnotetext{
1 En 2006, García Fernández abordó una introducción a Luis Enrique Torán, que había sido egresado en fotografía, en dirección y, después, profesor en la EOC. En el 2009, Luis Deltell propuso un modelo para el estudio de la etapa académica del alumno Antonio Lara y, en el año 2010 Asier Aranzubia Cob y Castro de Paz realizaron una investigación sobre la práctica Luciano, de Claudio Guerín.
} 
Erice dentro de la Escuela Oficial de Cinematografía y, por otro, la forja de su lenguaje cinematográfico y de su universo temático. Además, en dichos cursos este cineasta no solo aprendió las herramientas de la dirección cinematográfica sino que encontró una mirada propia.

Esta investigación se propone evidenciar las dos características que se repetirán en sus trabajos de la EOC y que perdurarán en la mayoría de su filmografía: la imposibilidad de la comunicación y la mujer como heroína de la trama. Además, de forma hilvana, este texto también quiere mostrar que el carácter documental de las obras recientes de Víctor Erice se encontraba presente de manera embrionaria en sus cortometrajes de la escuela.

La mayoría de los críticos que se han acercado al análisis de Los días perdidos han señalado la influencia de Michelangelo Antonioni. Sin duda, la estética del filme de Erice emula en parte la composición y el estilo visual del director italiano. Sin embargo, el rasgo más característico y que se transforma en una constante en sus prácticas es la problemática de la incomunicación. Los personajes del cineasta español parecen perdidos e incapaces de entablar un diálogo pleno con los otros.

\section{CURSO PRIMERO: "AL FINAL DE LA FIESTA SUBIERON A LA TERRAZA" (1960-1961)}

Los discentes que entraban en la Escuela Oficial de Cinematografía habían superado un riguroso sistema de pruebas. La mayoría de los candidatos que se presentaban a esta selección habían cursado otros estudios universitarios. Los que lograban matricularse podían considerarse afortunados y aunque sus conocimientos técnicos eran, a veces, básicos, su nivel cultural y capacidad de trabajo era altísimo (Blanco Mallada, 1990). La promoción de Víctor Erice vivió uno de los cambios más significativos de esta academia. Se renovaron el plan de estudios y el sistema de evaluación, se modificó la denominación -se pasó de Instituto de Investigaciones y Experiencias Cinematográficas a Escuela Oficial de Cine- matografía-, y se realizó la mudanza e instalación en un palacio en la calle de Monte Esquinza de Madrid. La EOC ganaba en prestigio, calidad y respetabilidad al equiparse a cualquier estudio superior. Los años de estancia de Erice fueron considerados por todos los estudiantes y profesores como el inicio de la "época dorada" de la escuela (Llinás, 1999).

En el curso inicial de la EOC los alumnos se enfrentaban con algunas pruebas de cámara, de las que se conservan solo retazos, y con un primer cortometraje. Este era una pieza muda y breve que se rodaba en una jornada. Según los años estos breves filmes podían ser más o menos complejos, pero en esencia lo que se pretendía evaluar era la capacidad del discente para planificar y realizar una puesta en escena básica. El material que se les ofrecía era escasísimo y las cámaras usadas eran las Paillard Bolex de cuerda, que solo aceptaba bobinas de treinta metros, lo cual dificultaba la planificación e impedía la filmación de planos largo. Casi la totalidad de los estudiantes escogía la narración documental. Estos directores noveles acudían a un asunto sobre algún lugar o suceso de Madrid: así fue la práctica de Josefina Molina (Cárcel de mujeres, 1964) entre otros. Muy pocos matriculados se arriesgaban a contar una narración de ficción; uno de estos intrépidos fue Erice.

Al final de la fiesta subieron a la terraza es un ejercicio excelente dentro de estos parámetros de producción. Destaca sobre los trabajos de sus compañeros por su enorme calidad técnica y su virtuosa puesta en escena. No en balde, más de la mitad de los alumnos de la EOC repetían el primer año la asignatura de Teoría y Práctica de la Dirección Cinematográfica que, sin embargo, Erice aprobó de forma brillante. A pesar de problemas de enfoque y de algún desaforo en el encuadre, este pequeño filme silente de cuatro minutos y cuarenta segundos presenta una fabulosa estructura narrativa y una planificación muy bien orquestada.

La historia de este cortometraje es aparentemente sencilla: una pareja de jóvenes, interpretada por Victoria Zinny y Julián Marcos, ascien- 
den a la azotea de un edificio. Es el crepúsculo de la madrugada. Visten con ropa de noche pero sus prendas se han arrugado y han perdido la elegancia. Ambos se tambalean, se sonríen: parecen ebrios y cansados tras una larga fiesta. Desde los primeros planos el hombre persigue a la mujer. Ella se escapa de las caricias, de las miradas y de los roces. Él la acecha. En un momento la protagonista queda arrinconada y cede a la insistencia del hombre, entran en un zaguán de un torreón y la cámara se aleja. Tras una elipse, entendemos que ha acontecido algo, tal vez, han hecho el amor. Él sale, la mujer se muestra apesadumbrada. Los dos se quedan en la azotea del edificio; entre ellos existe una enorme distancia y una falta total de comprensión.

En un primer lugar, sorprende la cálida interpretación. Los actores se comportan y se mueven con naturalidad, espontaneidad y sus gestos y actuaciones son efectivos. El coqueteo, la persecución, el encuentro y el posterior distanciamiento se reflejan perfectamente en sus rostros y en sus gestos. Tanto Zinny como Marcos se muestran como intérpretes adecuados. No menos interesante es la brillante puesta en escena. La composición de la práctica es sorpresiva. Erice coloca la cámara con diligencia acertada. $\mathrm{El}$ estilo posterior de este autor ya se reconoce en composiciones, encuadres y movimientos de cámara. Pocos creadores han mantenido una coherencia en su obra tan clara. Desde esta primera práctica hasta sus últimos proyectos audiovisuales, la mirada de Erice hacia sus personajes se centra en la preocupación por captar la realidad es la misma. Al igual que le ocurrió al poeta José Ángel Valente, que en su primer poema sintetizaba lo que sería toda su opera omnia: "cruzo un desierto y su terrible desolación sin nombre" (Valente, 1955), Víctor Erice, en su pequeña ópera prima, ya se posiciona como un creador con una mirada nueva.

En Al final de la fiesta subieron a la terraza se observan algunas de las constantes que se repetirán en toda la filmografía del director. Por un lado, el encuadre de dos personajes enmarcados tras una puerta, uno de ellos bajo el quicio y el otro al fondo; las jambas sirven para recortar el plano. Y, por otro, la utilización de un segundo personaje desenfocado mientras en primer término se presenta un plano medio cerrado de otro actor. Ambas composiciones se repiten en sus prácticas de la EOC y en sus dos largometrajes de ficción.

Uno de los elementos más característicos de las narraciones de Erice en la escuela es el protagonismo femenino. Ningún otro alumno de esta institución -ni siquiera Josefina Molina, ni Kathryn Walco, ni Cecilia Bartolomé, autora del cortometraje de mayor impacto feminista de la EOC Margarita y el lobo (1968-1969) - dedicó tanta atención a sus heroínas. En esta ocasión la trama no es la supuesta conquista de un hombre, sino más bien el miedo y la culpa que siente la joven ante el acoso del otro. Erice sitúa la cámara junto a ella, le dedica más primeros planos y nos deja percibir todo el recorrido psicológico que le acontece. La mujer es la que genera la acción. Mientras que al personaje masculino le embarga una ligera amargura tras el acto sexual -si es que se produce tal acto-, la joven es la que realmente lo padece y al final de la obra sentimos que es ella la que ha protagonizado y sufrido el acontecimiento narrado.

La clave de la práctica de Erice se encuentra en la elipsis utilizada. Durante la práctica, la joven parece temerosa y es seguida por el hombre; ella se aleja de sus caricias. No obstante, cuando empiezan los besos dentro del zaguán, la mujer los acepta y ambos se abrazan. El siguiente plano muestra al hombre saliendo de la torre y colocándose un fular sobre el cuello. El espectador no sabe si han sido solo unos besos o si han hecho el amor. Esta elipsis funciona del mismo modo que el famoso punto ciego de Casablanca que describe Žižek (143: 2006). En ambos casos es el público el que debe interpretarlo, es el espectador quien decide qué ha ocurrido durante esa elipsis. Como dice el pensador esloveno, el público con su criterio es el que debe cerrar lo narrado.

Es cierto que, en esta práctica, la puesta en escena, la sencillez del argumento y la natura- 
lidad de los actores nos conducen a pensar que se trata de un trabajo menor pero, sin embargo, al contemplarla detenidamente, se percibe precisamente lo contrario: "se evidencia", utilizando las palabras de Nancy (2008), la complejidad oculta. Erice se ha escondido para intentar atrapar un retazo de verdad. Al final de la fiesta subieron a la terraza representa un trabajo sorpresivo y valioso en donde el cineasta nos revela cómo el encuentro entre dos seres humanos termina en un fracaso comunicativo. Sirva de valoración que de los doce trabajos presentados en primero ese año, solo a Erice se le autorizó para pasar al siguiente curso (Archivo prácticas EOC).

\section{CURSO SEGUNDO: "ENTRE LAS VÍAS Y PÁGINAS DE UN DIARIO PERDIDO"}

Tras su primer año en la Escuela, Víctor Erice se mostró como uno de los estudiantes con más "dotes naturales para el cine” (Llinás: 79, 1999). En torno a él, junto con otros estudiantes del norte, se formó el "grupo vasco" (Blanco, 1990). El cineasta no solo había rodado una práctica excelente, sino que además comenzaba a destacar como crítico en la revista Nuestro Cine.

En 1962 todos los estudiantes de segundo curso se beneficiaron de un cambio político en España. Manuel Fraga, nuevo Ministro de Información y Turismo, había nombrado Director General de Cinematografía y Teatro a José María García Escudero, el cual apostó incondicionalmente por la EOC. Gracias a este apoyo, la dirección de la escuela modificó el reglamento para que los alumnos de segundo realizaran no una, sino dos prácticas en ese año académico. Los cortometrajes de este curso seguían siendo prácticas muy limitadas económicamente. Eran silentes y se rodaban con un escaso material. Sin embargo, se permitía a los egresados que filmasen en exteriores naturales, utilizaran varias jornadas y recurrieran a intérpretes de fuera de la institución. Estos ejercicios debían escribirse y ser aprobados antes de su filmación; se presentaban en forma de tratamiento sin diálogos y los tutores, tras su aceptación, autorizaban o prohibían sus respectivos rodajes.
En noviembre de 1961 Erice presentó dos borradores distintos que optaban a ser filmados: $\mathrm{Su}$ primera conquista y Entre vías. Aunque solo se rodó el último, resulta interesante hacer una breve descripción de ambos. Por una carta interna de la escuela firmada por M. A. Zabala sabemos que Víctor Erice había presentado los tratamientos "al efectuar su matrícula" de ese año (Archivo prácticas, Zabala 35/4). Estos textos se redactaron sin acotaciones de planificación. En una nota escrita a mano y firmada por el propio Erice se indica "ver guion técnico", por lo cual es lógico suponer que se adjuntó esta documentación.

En Su primera conquista la protagonista es una joven, en este caso nombrada como ELLA, que estudia en un instituto madrileño. Junto a un chico de su edad, al que se le nombra como ÉL, andan y ríen por los Jardines de Sabatini. Los dos se sonríen, se acercan y se alejan. Coquetean y juegan, se muestran inexpertos: a veces adultos y a ratos pueriles. Se sientan en un banco, sacan de sus carteras unas fotos y se las intercambian. ELLA mira con embeleso la foto del chico. Acude a su casa en donde cena con su madre y su padre. La chica de la casa escucha la radio y prepara la comida. ELLA se asoma a las ventanas del balcón con actitud melancólica. Después acude a su habitación. Esta había sido hasta hace poco el dormitorio de sus abuelos y aún conserva el retrato de sus antepasados. Intenta concentrarse en el estudio, pero pronto se levanta, toma la foto del chico y la "contempla desde todas las posiciones posibles". Ella se alza y se mira ante un espejo. Se prueba la chaqueta de los domingos, se contempla y acerca su cara hasta el espejo hasta casi chocar con él. Se quita la prenda y, con aire ausente, comienza a estudiar.

La madre entra con un vaso de leche caliente. La muchacha sigue estudiando. "Después, muy lentamente, se levantó y se echó sobre la cama, estiró su cuerpo y su cara se deslizó despacio a lo largo de la almohada. Luego fueron sus manos las que lo hicieron en una caricia inconsciente, hasta que hundió el rostro en la blanda superficie del almohadón. Estaba inmóvil, sobre la cama abierta, el pelo revuelto a lo 
largo de la espalda, teniendo solamente por testigos los rostros severos de sus antepasados y los ojos, siempre fijos, de aquella muñeca grande que estaba olvidada en un rincón" (Archivo de prácticas de la EOC).

Pocos proyectos cinematográficos durante el franquismo retrataron con tanta sutileza el descubrimiento de la sensualidad y sexualidad femenina como este ejercicio. Desgraciadamente, Erice no rodó está práctica, pero solo en el tratamiento encontramos elementos y propuestas de su universo. Una de ellas es la mujer en la ventana, la niña, adolescente, adulta o anciana que contempla tras los cristales de un balcón, imagen que será clave en Páginas de un diario perdido y en El espíritu de la colmena. Estas mujeres nada tienen que ver con las ventaneras madrileñas. No se parecen a esas castizas exhibicionistas o cotillas y a esa actitud un poco desinhibida que obligó a los monarcas españoles a rayar y esmerilar los cristales del Palacio de Oriente para que la princesas no "tomasen el vicio de la ventanera” (Burdiel, 2013). Todo lo contrario, las mujeres de Erice se acerca a los balcones, a los cristales, no a ser vistas ni a escudriñar a sus conciudadanos, sino a observarse a sí mismas, a buscar en su interior. La mayoría de las veces tras el balcón no se observa paisaje alguno, ya que llueve o los cristales son opacos o vidriados. Lo importante no es lo que acontece fuera de la casa, tampoco lo que sucede en la habitación, sino lo que ocurre en el interior de ellas.

Pero, sin lugar a dudas, el eje central de $\mathrm{Su}$ primera conquista es, precisamente, el título del tratamiento: el primer triunfo, el primer descubrimiento. Toda la narración se centra en una iniciación, en cómo esta adolescente abandona la niñez para entrar en la juventud. No hace falta recordar que tanto en El espíritu de la colmena como en $\mathrm{El}$ sur, estos son los tema capitales de la trama.

Sin embargo, el tratamiento que Erice optó por filmar fue Entre vías, que se tituló Entre las vías. En él, los protagonistas vuelven a ser nombrados de forma anónima como ELLA y ÉL. Ambos viven en un arrabal marginal de Madrid.
Se trata de la historia de un joven matrimonio de clase pobre. La narración comienza cuando ELLA y ÉL se desperezan y se levantan de la cama. La estancia que sirve de dormitorio y sala de estar es mísera. La pareja desayuna y el hombre marcha a la calle. El barrio paupérrimo se extiende a lo largo de las vías del tren. A ambos lado de las catenarias se acumulan las casas humildes y chabolas de los recién emigrados a Madrid. El hombre llega al centro de la ciudad.

Parece, por la actitud del protagonista, que se trata de un ratero o un descuidero. ÉL deambula a la caza de una víctima. En un momento comienza a seguir a un cobrador. Entra tras él en un inmueble, sube las escaleras y, en la planta principal, le aborda y le intenta robar. La víctima gesticula y grita -la práctica es silente-, los vecinos salen a su socorro y ÉL huye aprisa por las calles. El joven descorazonado anda por las afueras, entre vagones de tren abandonados, vías muertas y fábricas viejas. Todo el barrio trasmite una miserable sensación de herrumbre. En un puente del ferrocarril se detiene y mira hacia el suelo: la tristeza y la mirada evidencia la intención del suicidio. Pero el silbido de un tren despierta al hombre de su terrible melancolía y termina por no saltar y descender al descampado. Allí, la mujer le socorre. ELLA comprende lo que ha pasado, lo consuela, lo acaricia e intenta animarle. El hombre avanza solitario por la calle y la mujer, en actitud comprensiva y de cariño, le sigue.

En apariencia Entre las vías es la práctica más disonante de Víctor Erice. Su temática, los robos y hurtos poco se asemejan a lo que se trata en las otras obras y películas posteriores. Del mismo modo, el protagonismo masculino es único en la filmografía de ficción de Erice -solo en $\mathrm{El} \mathrm{sol}$ del membrillo (1992) se presentará a otro hombre como protagonista-. Y, sin embargo, al contemplarse se descubren muchos de los elementos centrales de este cineasta: la terrible incomunicación de los protagonistas, el placer por retratar las pequeñas cosas, el detalle de la vida cotidiana y el ferrocarril como símbolo y metáfora. Además Entre las vías presenta un marcado carácter documental, se trata de un reflejo de los barrios 
periféricos de la ciudad madrileña y esto entra en sintonía con las últimas obras del cineasta.

La incomunicación en el matrimonio -o entre hombre y mujer- es una constante que se repite en todas los trabajos que se conservan de Erice. Esposa y esposo, hija y padre, amada y amado parecen no entenderse nunca en el cine de este cineasta. Esta incomunicación no supone ni odio, ni recelo, ni infidelidad, sino simplemente distanciamiento y frialdad. Los protagonistas están alejados y cerrados en sí mismo: guardan sus misterios.

Si hay algo que sorprende en el Erice estudiante es su esmero por retratar lo cotidiano, el detalle de la vida diaria. Este afán no debe confundirse con una herencia neorrealista, ni mucho menos. Desde Entre las vías y hasta sus obras más recientes, Erice poetiza el detalle. La actividad habitual, lo cotidiano, se cubre de poesía y de simbolismo. No se trata de mostrar cómo desayuna un matrimonio obrero en Madrid, sino de representar el ritual o el sacramento del desayuno. Esta atención hacia lo mínimo ya se había descrito en el tratamiento de Su primera conquista pero es en esta práctica filmada y en Páginas de un diario perdido donde, definitivamente, Erice decide narrar sus tramas con acciones en apariencia anodinas.

No menos simbólico es el uso del tren y las vías de hierro. Los personajes de casi la totalidad de su filmografía viven cerca, o cercados, por el tren. En Entre las vías se habla del "barrio divido por las vías”, en El sur y El espíritu de la colmena representan el límite de lo conocido; en sus obras los protagonistas no suben al tren. Lo contemplan, lo miran y lo temen, pero no llegan nunca a viajar en él. Entre las vías es la primera vez que aparece el ferrocarril y su carga simbólica es fortísima. El barrio está separado de la ciudad por el binario y por un cementerio de vagones y locomotoras viejas. Los protagonistas no aspiran a ascender al ferrocarril o a viajar, sino que tan solo se conforman con verlo. No es casual que sea el sonido de un tren, de la esperanza de un cambio, el que impida el suicidio del protagonista.
Entre las vías es una práctica compleja de evaluar técnicamente. Gracias a una reciente investigación podemos valorar su calidad y sus defectos (García Marcos, 2016). La obra presenta algunos problemas de enfoque y movimientos bruscos. También sorprende por el uso de las ópticas zoom, algo insólito en el cine de Erice. La composición de la práctica es de nuevo elegante y bella. El operador fue Luis Cuadrado, que destacó en todos sus ejercicios estudiantiles (García Marcos, 2016). De nuevo se rodó con la Paillard Bolex de cuerda, como su primera práctica, por ello Erice utiliza en su planificación los planos breves y recurre con frecuencia a los fuera de campos, a las escenas fragmentadas y sabe idear una excelente secuencia para el intento de asalto.

Sin embargo, existe algún bloque menos logrado. Tal vez el momento que resulta más débil de la práctica es la decisión del suicidio. Mientras que en el tratamiento está perfectamente descrito en la relación final, su puesta en escena resulta evidente. Leamos la descripción en el texto: "El hombre estaba de nuevo junto a las vías. Aquellas vías que dividían el barrio en dos y que ahora pasaban por encima de un puente. Llegó a la mitad del mismo y se detuvo. Miró hacia abajo, hacia la carretera empedrada que serpenteaba a sus pies, como tratando de diferenciar los colores de las piedras. Sus manos se crisparon sobre la barandilla, su rostro se contrajo, su mirada se hizo más fija. Permaneció así unos instantes. Luego sus manos y su rostro se aflojaron; quizá fue el frío del metal y del viento, o la presencia de una locomotora haciendo maniobras las que le hicieron alejarse" (Archivo de prácticas de la EOC).

Erice resuelve esta escena con planos medios del hombre mirando desde la baranda del puente hacia el vacío y el camino embarrado de debajo del puente. Estos planos se refuerzan con dos zoom in -avance de carro de las lentes zoom - uno hacia el rostro del joven, pasando de plano medio a primerísimo plano y otro del plano general del vacío hasta plano detalle de los charcos. Esta planificación resulta algo efectista 
y difiere mucho del estilo pausado, relajado y nada evidente del posterior cine de Erice. Entre las vías, como ocurrirá con Los días perdidos, permite una reconstrucción documental de los espacios madrileños. Describe con esmero las condiciones sociales del barrio obrero y ofrece una importante intención documental. Es evidente que el cineasta pretende atrapar lo cotidiano de sus personajes pero también de la propia ciudad y sociedad que filma.

Tras la conclusión de este cortometraje, entre enero y marzo de 1962, Víctor Erice propone y presenta a la escuela dos nuevos tratamientos para su segunda práctica de ese curso. En este caso ofrece dos historias muy distintas: Retorno de un tiempo viejo, fechado en enero de 1962, y Páginas de un diario perdido, fechado en marzo de 1962, (Archivo Prácticas EOC). Aunque solo se conserva un copión de trabajo del último, los dos presentan elementos fundamentales y troncales en la filmografía de Erice: la mujer como protagonista, el encuentro y desencuentro con la infancia y el hogar paterno, el ámbito familiar, etc.

Retorno de un tiempo viejo puede ser leído como una primera versión de Los días perdidos: aunque las diferencias entre ambos son evidentes, el asunto central es el mismo. Una mujer, Isabel, regresa a la casa familiar, un antiguo palacete. Arriba en un vehículo extranjero. Entra en el jardín abandonado. Un viejo guardés le abre la puerta de la vivienda y ella deambula por las salas que están cubiertas de polvo y envejecidas. Isabel entra en las distintas estancias y recobra imágenes del paso. Es, sobre todo, el piano el que le devuelve a su infancia, a las largas horas de estudio musical y a la mirada atenta de su madre. Los padres de Isabel han fallecido y ahora está sola en el hogar familiar. Debe decidir hacer algo, pero siente que ese lugar, ese espacio donde se custodian los retratos de la familia, los muebles heredados de generación en generación y, también, donde se guardan sus recuerdos de infancia, ya no le pertenece. Isabel contempla la casa y sale hacia su vehículo. Por el jardín la lluvia le empapa pero ella no la siente. Antes de subir al coche despierta de su ensueño, se sacude el agua de la ropa y mira la casa por última vez.
La historia, como decíamos, recuerda el asunto de Los días perdidos: una mujer que retorna del extranjero, tras la muerte de su último progenitor. Sin embargo, las diferencias son también muy relevantes. El aspecto más logrado de este tratamiento es el tono poético. Toda la práctica es un largo e inquietante tiempo muerto. Erice opta por no desvelar nada, por ello los acontecimientos que se suceden son mínimos y revelen poca o nada información. El fututo filme, que debería ser silente, sería muy complejo en su narración. Así lo detallaban los profesores de prácticas: "Es muy difícil hacer este ejercicio con las calidades que se apuntan en el guion. En todo caso es (una) película personal, de estilo, y el autor debe intentar la experiencia" (Archivo prácticas PRA/35/4).

En Retorno de un tiempo pasado se agolpan los temas, los detalles y la estética propia de este director: el casón paterno a las afueras de la ciudad, próximo al pueblo pero, a la vez, distante; La mujer que regresa del extranjero y ya no se identifica con su vida; la infancia como irrecuperable y la incomunicación entre generaciones y personas. Aunque los tutores de la EOC autorizaron su rodaje, el estudiante optó por presentar un nuevo tratamiento titulado Páginas de un diario perdido que filmaría a largo de ese año. Esta práctica, la A-8713, es la peor conservada. Carece de cartones e inicios de título de crédito o finales. Solo se puede identificar al compararla con el tratamiento conservado en el archivo. Además, hay cortes de planos abruptos y el cambio de escenas y bloques es brusco. Gracias al asesoramiento del propio Víctor Erice podemos pensar que se trata de un copión de trabajo y que el montaje definitivo se encuentra desaparecido.

La protagonista de esta práctica se llama, de nuevo, Isabel. Es una niña de dieciséis años con un "aire prematuramente maduro". Durante una tarde de domingo, la joven contempla la lluvia tras los cristales de un balcón. Isabel se sienta junto la mesa camilla y comienza a estudiar, pero pronto recuerda a Juan, su novio del Instituto, con el que suele pasear por los jardines cercanos al Viaducto. La joven sale de su habitación 
y entra en el salón de la casa. Allí la madre cose junto a un balcón, y la anciana abuela descansa adormilada en una tumbona. Isabel acaricia el piano y, distraída, toca algunas notas. La abuela se despierta. La nieta se sienta a su lado y ambas miran un álbum de fotografías familiares; algunas de las imágenes están descoloridas. La anciana sonríe.

Isabel vuelve a su habitación y regresa al estudio. Pero es inútil. De un golpe se alza hasta la puerta y cierra con cerrojo. De entre los papeles, saca una novela rosa y comienza a leer. Pronto se cansa y se levanta, se contempla en el espejo de su habitación. Entonces toma el gato de la casa e inicia un extraño juego sádico con el animal. "Lo miró de cerca mientras lo acariciaba. Luego, sin embargo, convertía la caricia en presa alrededor del cuello del animal. Este se debatía unos momentos, hasta que ella lo volvía a acariciar. Y así se repetía el juego. Esta vez el gato la arañó. Isabel se miró la sangre frente al espejo. Vio su figura en el cristal y se acercó. Se llevó el dedo sangrante a los labios y extendió la sangre por los mismos a la manera de un extraño carmín. Terminó chupando afanosamente la sangre" (Archivo prácticas, PARA/35/4). Isabel de nuevo se contempla, con los labios ensangrentados, ante el espejo de su cuarto.

Al tratarse de un copión de trabajo Páginas de un diario perdido presenta un inevitable carácter inacabado. Silente, con problemas de cortes, sin créditos y con un final abrupto, trasmite una sensación de obra incompleta y de ensayo estudiantil más que de práctica cerrada. Además del carácter fragmentario, la filmación se hizo en el plató de la escuela y la decoración de la misma es pobre. A pesar de todo, Erice encontró algunas soluciones atractivas en este ejercicio. De nuevo, se suceden las composiciones precisas y claras: encuadres con las jambas de las puertas, las mujeres situadas en línea de profundidad haciendo que el pequeño estudio del EOC parezca más amplio de lo que es en realidad y, otra vez, utiliza las ventanas y balcones para centrar la mirada no en el exterior, sino en el rostro de las protagonistas que miran un paisaje que el espectador nunca contempla.
Dos son los momentos más destacados de la propuesta: el momento en el que las tres mujeres se encuentran en el salón y el juego final con el gato. El primero de ellos es un ejercicio bellísimo. Se trata de un estudio de las tres edades de la mujer. Erice apela y se inspira claramente en las composiciones europeas sobre este tema. Así, las tres reflejan pasos claves: adolescencia, adultez y vejez. Este estudio del tiempo se refuerza con el uso del álbum donde contemplan imágenes de la familia.

Pero el momento más audaz e inquietante es el juego y maltrato al animal. Como en Su primera conquista, Erice se interesa y mira al detalle lo que hace una adolescente sola en su cuarto cuando ha cerrado con pestillo la puerta. La joven se contempla en el espejo y, tras ojear una novela rosa y pensar en su novio, toma un gato al que estrangula. La práctica no contiene más que dos primeros planos: uno dedicado al animal que se ahoga entre las manos de Isabel y el otro encuadre de la propia chica que se contempla ante el espejo, su dedo sangra y ella se pinta con su propia sangre los labios. La escena es compleja por esa extraña mezcla entre la crueldad pueril y el descubrimiento de la sensualidad de una adolescente casi mujer (Ehrlich, 2009). Sin duda, una vez más, el estudiante vasco vuelve a concluir su trabajo mostrando a su protagonista sumida en una enorme incomunicación; el descubrimiento de la madurez no le sirve para entenderse con su madre y abuela, sino para distanciarse aún más.

$\mathrm{Al}$ igual que pasó en el primer curso, Erice es uno de los pocos alumnos que aprobó en primera convocatoria. Gracias a los trabajos de este curso, se le permite matricularse en tercero, en el año académico 1962-1963 (Archivo prácticas EOC) junto a los estudiantes: Pascual Cervera, Angelino Fons, Pedro Balañá Bonvehí y Wilhelm Ziener.

\section{CURSO TERCERO: "LOS DÍAS PERDIDOS"}

La práctica final de Víctor Erice, Los días perdidos, es la más estudiada de todas ellas. Algunos 
autores, como Lucio Blanco, la consideran como uno de los grandes filmes que se hicieron en la escuela. Ha sido analizada en diversos trabajos: Arocena, Pena y Ehrlich (2009) entre otros. Además, se ha proyectado en múltiples ocasiones y se ha exhibido en filmotecas y centros de arte por todo el mundo. Su acceso es más fácil, por ello no parece oportuno realizar un resumen detallado del argumento. Exponemos solo un pequeño resumen: Isabel, una joven madrileña que ha emigrado a París, vuelve a la casa natal para encargarse de la herencia de su padre que ha fallecido recientemente. Junto a una tía visita la tumba de su padre. Después queda con una amiga de la infancia que le comenta que es afortunada por haberse ido a Francia. Isabel regresa a la vivienda familiar y se encuentra con Juan, antiguo novio. Ambos deambulan por la ciudad, hablan del pasado y él le interroga sobre el motivo de su huida a París. Ella no responde. Acuden a un locutorio, donde Isabel habla en francés con su hijo y su esposo. De regreso al barrio, Juan la besa violentamente sin su consentimiento. Isabel logra zafarse de él y regresa a París.

Para la mayoría de los autores esta película se inspira en el cine de Antonioni. Así lo veían Pena y Ehrlich. Sin duda, la presencia de la estética del director italiano está en Los días perdidos como se encuentra en casi todas las prácticas de la EOC de esos años. El director de la institución, José Luis Sáenz de Heredia, lo decía maliciosamente en la apertura del curso académico de 1962: "En cine, y más acusado entre los que lo empiezan al iniciar su juventud, es fácil infectarse de esa gripe de la moda, y así vamos pulsando cómo un año todos admiran a Fellini, para abandonarlo en bloque al siguiente y transbordar a Bergman y apearse luego todos corriendo de ese tranvía para no quedarse sin asiento en el autobús de Antonioni" (Sáenz de Heredia, 1962).

Es cierto, como bien observan unos y otros, que en Los días perdidos Erice propone una estética de encuadre y de composición muy cercana al universo de Antonioni. Planos largos de duración y puesta en escenas que se construyen con una gran profundidad de campo. Los espacios siempre presentan grandes fugas filmadas -con ópticas angulares- y los personajes parecen deambular de un lado a otro como hacen los protagonistas de La aventura ( $L^{\prime}$ Avventura, 1960) y El eclipse (L'eclisse, 1962). El formato panorámico escogido aumenta esta sensación de amplitud y de vacío. El largo paseo de Isabel y Juan por los descampados -el mismo barrio en el que ya había rodado Entre las vías-, las fábricas abandonadas y las vías en desuso recuerdan indudablemente a las secuencias urbanas del italiano. Pero esta influencia es, en suma, menos importante que otra más llamativa y relevante: el deseo de mostrar la incomunicación de los personajes. Este es el tema constante y subterráneo que aparece en todas sus prácticas de la EOC.

Sin duda, los personajes solitarios y el ambiente de imposible contacto se encuentran en las películas de Antonioni. En todas ellas parece difícil, o inalcanzable, una relación plena. En las prácticas del cineasta español está sensación se repite, pero lo importante no es emular la superficie sino indagar en la esencia de esta problemática. En 1961, el propio Erice había escrito este interesante comentario sobre el cineasta italiano: "En el terreno opuesto a un Beckett, y dentro del campo cinematográfico, tenemos el magnífico ejemplo de Antonioni. La incomunicación no es para este la consecuencia de una naturaleza humana inmutable, sino producto de un momento histórico, de una clase concreta, de una moral determinada. La incomunicación no es para él un punto de partida, sino un resultado" (Erice: 48 y 49,1961$)$.

La crítica que hace el cineasta se puede aplicar casi milimétricamente a sus propios filmes de la EOC. En todos ellos se repite el esquema propuesto: la incomunicación no se manifiesta en el inicio de la trama, sino que es la conclusión de las decisiones de los protagonistas y del contexto social y político, el franquismo de los años sesenta. Así ocurre en los ejercicios de los dos cursos iniciales y de forma clara se repite en Los días perdidos. Isabel regresa a Madrid; ha logrado una vida plena en París, donde se ha casado y tiene un hijo. Su esposo parece tierno por la lla- 
mada telefónica y, por las palabras que dirige la protagonista a su amiga Pilar, su hijo es encantador. Entendemos que es feliz en Francia. Sin embargo, su regreso a Madrid le sitúa en una posición de total incomunicación, primero con Juan, luego con sus recuerdos y, en último caso, con su propio país.

El libreto original conservado en la Filmoteca Española comienza con un poema de Juan de la Encina que no se incluyó en la película: “Triste España sin ventura / todos te deben llorar, / despoblada de alegría / para nunca en ti tornar". (Archivo Prácticas EOC). Sin duda, el personaje de Isabel sentía estas palabras en el final de Los días perdidos; su decisión es volver a París para no regresar más a España. Se produce una incomunicación total de ella con sus contemporáneos y con su momento histórico.

En el cine de Erice no se tratan los grandes acontecimientos de la historia, sino la vida de seres pequeños, de niñas que viven en ciudades de provincia o aldeas, de mujeres - como Isabelque regresan a la casa paterna por unos días, etc. Es precisamente esta mirada a la intrahistoria lo que le permite revelar la incomunicación que sufren los protagonistas por sus decisiones personales, pero también por el contexto en el que viven. Isabel puede haber reconstruido su vida, pero el precio que debe pagar por ello es dar por “perdida” toda su vida previa en España.

\section{CONCLUSIONES}

Los trabajos realizados por Víctor Erice durante su estancia en la EOC han sido ignorados y abandonados por la crítica cinematográfica. Tan solo su práctica final ha despertado interés y se le ha considerado como una de las mejores prácticas realizadas en ese centro educativo. Sin embargo, al analizar el material inédito que se conserva en el Archivo de Filmoteca Española, así como la contextualización de los trabajos audiovisuales, se puede entender que estas obras -cuatro guiones no filmados, tres cortometrajes mudos y uno sonoro- representan un eslabón clave en la formación del cineasta español.
No se trata de meros trabajos educativos sino que, ya desde sus primeros ejercicios, Víctor Erice plantea una mirada con una estética propia y con una problemática centrada en dos temas: la mujer como heroína y, sobre todo, la incomunicación humana. Así, en todas sus piezas se aprecia un detallado estudio de la puesta en escena y la planificación. Este cuidado le permitió destacar sobre sus otros compañeros de promoción y ser uno de los pocos discentes de dirección que lograran diplomarse aprobando curso por año.

Pero es, sin duda, el desarrollo de la problemática de la incomunicación humana lo que más sorprende de sus primeras películas. Erice es capaz, desde sus trabajos iniciales, de desarrollar y presentar un tema complejo, buscando siempre una mirada propia y nueva. La incomunicación de las personas, en especial de las protagonistas heroínas, será el eje central de la creación durante su etapa formativa así como se encontrará, también, en el núcleo de sus dos primeros largometrajes de ficción. 


\section{AGRADECIMIENTOS}

Esta investigación habría sido imposible sin la ayuda y la generosidad de la Filmoteca Española (Lourdes Odriozola, Trinidad del Río, Eduardo Sastre y todo el personal de la Biblioteca de la Filmoteca Española). Ha sido importante el apoyo de los bibliotecarios de la Facultad de Ciencias de la Información de la UCM y la ayuda de la Beca de Fundación del Amo que permitió al autor viajar a Berkeley, University of California, al encuentro An Open Window: Víctor Erice. Por último, el autor desea hacer constar su especial agradecimiento a Víctor Erice por sus conversaciones y por sus respuestas a las múltiples cuestiones efectuadas sobre este texto.

\section{FUENTES}

El material que se ha usado para esta investigación se encuentra en gran parte inédito. Salvo la práctica de tercero, Los días perdidos (19621963), el resto de los trabajos no han sido analizados ni se han distribuido o estrenado. Algunos de ellos se citan en monografías, libros, en páginas webs o artículos sobre el director y en el catálogo de prácticas de sobre la EOC editado por Filmoteca Española, pero todos estos contienen lagunas, errores y erratas.

Muchos de estos trabajos resultan difíciles de citar y pueden conllevar a equivocaciones. Por ese motivo, consideramos oportuno presentar a continuación la documentación de la filmografía de nuestro corpus de estudio. Los títulos que le damos a las prácticas son aquellos que figuran en los cartones de las mismas. En caso de que no se conserven en las bobinas de celuloide, se utiliza el nombre que Víctor Erice les dio en sus tratamientos o guiones presentados en la EOC.

\section{Filmografía}

\section{- Al final de la fiesta subieron a la terraza}

También citado como: La terraza, En la terrza, Y al final de la fiesta subieron a la terraza, Y al final de la fiesta subieron a la azotea, La azotea, En la azotea

(1960 - 1961) IIEC
Director: Víctor Erice

Guion: Víctor Erice

Fotografía: Miguel A. Martín

Duración: 4 minutos 40 segundo

Formato: 16 mm, cámara usada: Paillard Bolex de cuerda.

Materiales conservados: Copia de trabajo

Intérpretes: Victoria Zinny y Julián Marcos

Ficha Filmoteca Española: A - 8991

\section{- Entre las vías}

También citada como: Entre vías, En las vías, Entrevías, En las vías.

(1961 - 1962) IIEC - EOC

Director: Víctor Erice

Guionista: Víctor Erice

Fotografía: Luis Cuadrado

Segundo operador: Fernando Arribas

Foquista: Raúl Peña

Ayudante de dirección: G. Sebastián de Erice

Duración: 9 minutos

Formato: 16 mm, cámara usada: Paillard Bolex de cuerda.

Materiales conservados: Telecinado

Intérpretes: Luisa Muño, Norberto Arribas, Raúl Tartaj

Ficha Filmoteca Española: A - 8992

\section{- Páginas de un diario perdido}

No se conserva el cartón del título en la práctica, por ello se toma el nombre del tratamiento entregado antes del rodaje. Se trata de un copión de trabajo.También citada como: Diario perdido, Páginas de un diario

(1961 - 1962) IIEC - EOC

Director: Víctor Erice

Guionista: Víctor Erice

Fotografía: (No consta)

Segundo operador: (No consta)

Foquista: (No consta)

Ayudante de dirección: (No consta)

Duración: 12 minutos 10 segundos

Formato: $16 \mathrm{~mm}$

Materiales conservados: Telecinado - Copión de trabajo

Intérpretes: (No consta)

Ficha Filmoteca Española: A - 8713 


\section{- Los días perdidos}

(1962-1963) EOC

Director: Víctor Erice

Guión: Víctor Erice

Fotografía y Cámara: Fernando Arribas

Foquista: Francisco Madurga

Foto-fija: Antonio L. Ruiz

Decorados: Jesús M. Herrero

Sonido: Arando R. González-Posada, Francisco G.

Pérez, Eduardo Valero

Montaje: Ana María Romero Marchent

Ayudante de montaje: Llanos Sánchez

Maquillaje: María Luisa de la Torre

Ayudante de dirección: Mario G. Martín

Script: Pedro Costa

Jefe de producción: Antonio Matilla

Ayudante de producción: Alfonso

Cortés-Cavanillas

Intérpretes: Luisa Muñoz, Francisco Andrada,

María Elena Flores y María Teresa Dressel

Duración 41 minutos

Formato $35 \mathrm{~mm}$.

Materiales conservados. Negativo. Copia standard Intérpretes Luisa Muñoz, Francisco Andrada, Mo

Elena Flores, Ma Teresa Dressel

Ficha Filmoteca Española: A - 2174

\section{Tratamientos y guiones depositados en el Archivo de la EOC}

- Entre vías (fechado en noviembre de 1961, tratamiento de Entre las vías)

- Su primera conquista (fechado en noviembre de 1961)

- Retorno de un tiempo viejo (fechado en enero de 1962)

- Página de un diario perdido (fechado en marzo de 1962)

- En la ciudad (fechado el curso académico de 1961-1962)

\section{BIBLIOGRAFÍA}

ALBERICH, Ferrán. "El Instituto de Investigaciones y Experiencias Cinematográficas y la Escuela Oficial de Cinematografía en el Cine Español", en LLINÁS, Francisco. 50 años de la escuela de cine. Filmoteca Española, Madrid, 1999, pp. 11-32.

ARANZUBIA COB, Asier y CASTRO DE PAZ, José Luis. "Desmontando el discurso televisivo: Luciano (Claudio Guerín Hill, 1964-1965)", Zer, Volumen 15, Num. 29, 2010, pp. 13-30.

ARQUERO BLANCO, Isabel. Estudio descriptivo de "El espíritu de la colmena" (Víctor Erice, 1973). Universidad Complutense de Madrid, 2012, Tesis Inédita.

AROCENA, Carmen. Víctor Erice, Cátedra, Madrid, 1996.

BLANCO MELLADA, Lucio. IIEC y EOC Una escuela para el cine español. Universidad Complutense de Madrid, 1990, Tesis Inédita.

BORDWELL, David. Figures Traced in Light. On Cinematic Staging, University of California, 2005.

BURDIEL, Isabel. Isabel II. Una biografía, Taurus, Madrid, 2010.

CERRATO, Rafael. Víctor Erice. El poeta pictórico, Ediciones JC, Madrid. 2006.

DELTELL, Luis. "Boris (1966) y El perro (1977). Estudio de dos guiones escritos por Juan Antonio Porto". Área Abierta. Vol. 14 n01. Marzo 2014.

DELTELL, Luis. "La mujer como sujeto: Josefina Molina en la Escuela Oficial de Cine". SIGNA. Revista de la asociación española de semiótica, Vol. 24, 2015.

EHRLICH, Linda (Edición). The Cinema of Víctor Erice: An Open Window, Lanham, MD, Scarecrow, 2009.

ERICE, Víctor: "Plácido de Luis Berlanga", Nuestro cine, n05, noviembre, 1961.

GARCÍA FERNÁNDEZ, Emilio C. (Coordinador). Antonio Lara, la enseñanza de la imagen. Departamento de Comunicación Audiovisual y Publicidad 1, Madrid, 2009.

GARCÍA FERNÁNDEZ, Emilio C. (Coordinador). Torán. Escritor de la luz. Homenaje a Luis Enrique Torán Peláez. Universidad Complutense de Madrid. Departamento de Comunicación Audiovisual y Publicidad 1, Madrid, 2004.

GARCÍA MARCOS, Eva. Luis Cuadrado en la Escuela Oficial de Cine. Universidad Complutense de Madrid, 2015, TFM inédito. 
LATORRE, Jorge. Tres décadas de El espíritu de la colmena, Ediciones Internacionales Universitarias, Madrid. 2006.

LLINÁS, Francisco. 50 años de la Escuela de Cine. Filmoteca Española, Cátedra, Madrid, 1999.

PENA PÉREZ, Jaime J. "Notas sobre un estilo cinematográfico: Víctor Erice", En Actas del IV Congreso de la A.E.H.C., Madrid, Editorial Complutense, 1993, pp. 299-309.

NANCY, J. L. La evidencia del filme. El cine de Abbas Kiarostami, Errata naturae, Madrid, 2008.

RODRÍGUEZ MERCHÁN, Eduardo. "La enseñanza del cine en España: perspectiva histórica y panorama actual", Comunicar, Vol. 25, № 29, 2007, pp. 13-20.

SÁENZ DE HEREDIA, José Luis. "Escuela española de Cinematografía: Discurso", Nuestro cine, n05, noviembre, 1961.

VALENTE, José Ángel. A modo de esperanza, Adonais, Madrid, 1955.

ZUNZUNEGUI, Santos. "Escribir el cine. La pasión cinéfila de Víctor Erice", L'Atalante, no 18, 2014.

ŽIŽEK, Slavoj. Lacrimae Rerum. Ensayos sobre cine moderno y ciberespacio, Debate, Madrid, 2006.

\section{OTRAS FUENTES DOCUMENTALES}

Archivos del IIEC y EOC conservados en la Filmoteca Española:

Expediente promociones 1961-1962, 1962-1963 y 19631964. 